\title{
Double-scope rendezvous technique: a safe way to perform an endoscopic ultrasound-guided ileorectal anastomosis after complete stenosis
}

A 56-year-old man underwent subtotal colectomy for sigmoid volvulus with coIonic necrosis. Despite a surgical reintervention to redo the ileorectal anastomosis with protective ileostomy, he presented again a complete stenosis without any persistent lumen on computed tomography (CT) and endoscopic evaluation. Therefore, no guidewire could be placed through the stenosis to perform dilation or stenting. With concern about a significant risk of complication of a third surgical intervention and after a multidisciplinary discussion, an endoscopic ultrasound (EUS) recanalization was planned. To assure the procedure, a rendezvous technique was preferred ( $\vee$ Video 1 ).

Under general anesthesia, a colonoscope was inserted through the ileostomy and pushed to the ileal side of the complete stenosis ( $\mathbf{F i g . 1} \mathbf{1}$ a). A linear echoendoscope was inserted in the rectum ( $\triangleright$ Fig.1b). A saline solution with carmine was instilled through the waterjet channel to fill the ileum allowing excellent visualization in the transrectal EUS view. After puncture with a 19-gauge needle and guidewire insertion with a transileal view confirming the right positioning, a 20-mm diameter electrocautery-enhanced lumen-apposing metal stent (LAMS) (Boston Scientific, Marlborough, Massachusetts, USA) was placed. Two months later, ileostomy was closed using a local approach after initial endoscopic control (> Fig.2). After stoma removal, the LAMS spontaneously migrated, and the anastomosis was large and permeable at the 6-month follow-up (> Fig. 3).

Although stenosis of ileorectal anastomosis apart from Crohn's disease is a rare complication, complete stenosis can be very bothersome [1]. Reoperation may require resecting even more of the rectum or even making an ileoanal anastomosis with more complications and the poorest functional outcomes. EUS-guided LAMS placement has been described

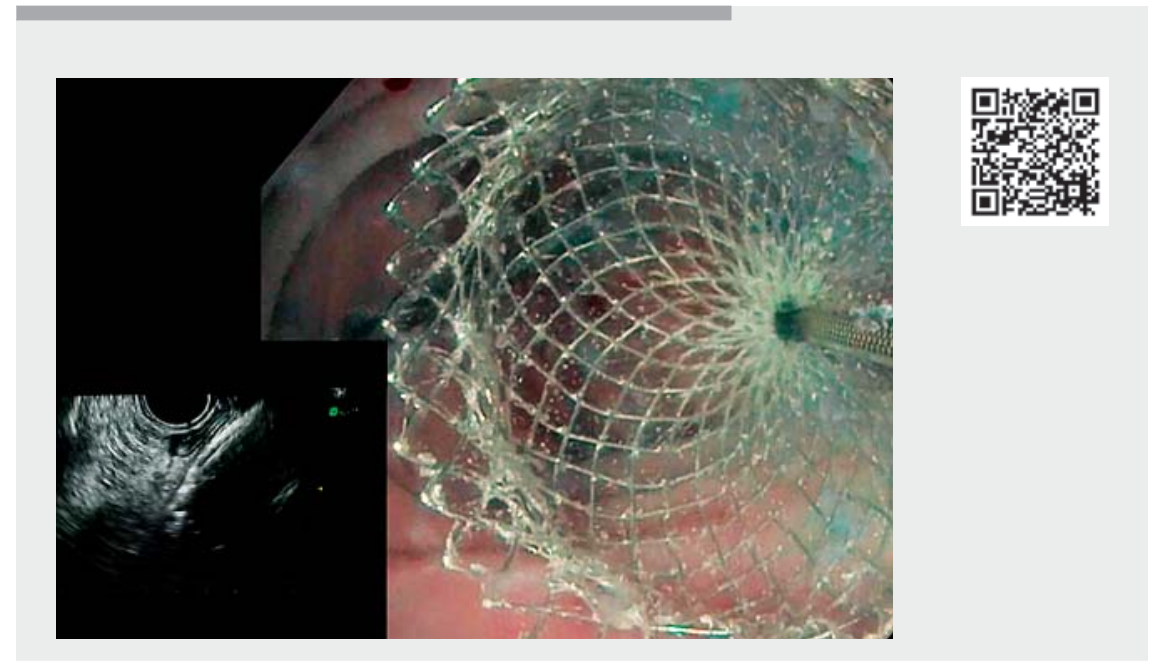

Video 1 Double-scope rendezvous technique: a safe way to perform an endoscopic ultrasound-guided ileorectal anastomosis after complete stenosis.
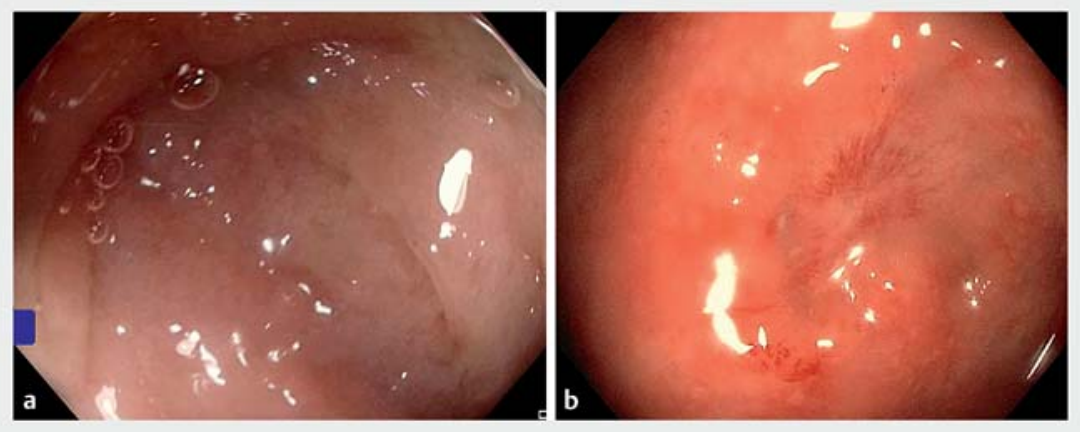

Fig. 1a lleal side of the stenotic anastomosis. b Rectal side of the stenotic anastomosis.

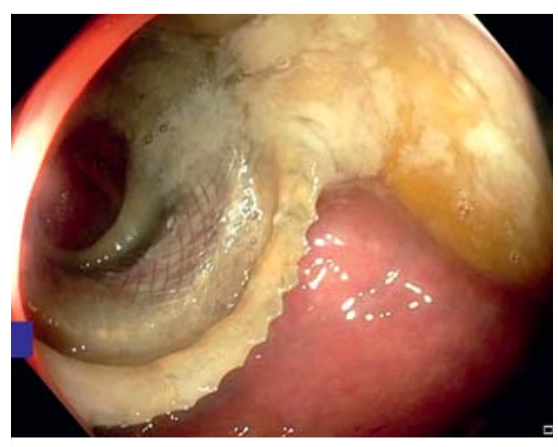

- Fig. 2 Endoscopic control before stoma removal showing permeability of the lumen-apposing metal stent.

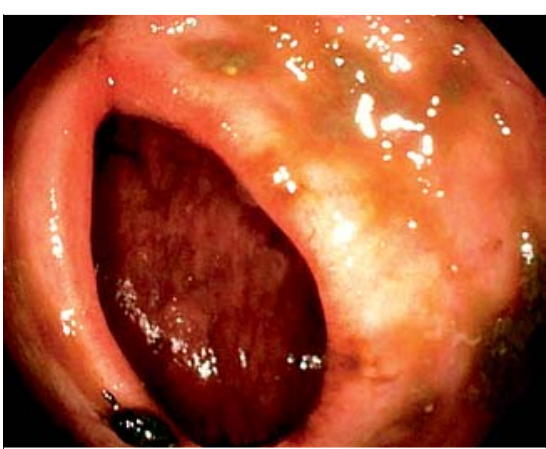

Fig. 3 Large and permeable anastomosis after stoma removal and migration of the lumen-apposing metal stent. 
for colorectal stenosis [2-4]. However, ileorectal anastomosis can be more challenging owing to the disparity in lumen size and thickness between the ileum and rectum. The rendezvous technique with direct filling and visualization of the ileal side of the stenosis can ensure safety throughout the procedure.

Endoscopy_UCTN_Code_TTT_1AQ_2AF

\section{Competing interests}

Jean-Baptiste Chevaux \& Jérémie Jacques have been speaker for Boston Scientific.

The authors

Marion Schaefer ${ }^{1}$, Julie Leclerc ${ }^{2}$, Jérémie Albouys $^{3}$, Thomas Lambin ${ }^{4}$, Jérémie Jacques $^{3,5}$, Thibaut Fouquet ${ }^{2}$, Jean-Baptiste Chevaux ${ }^{1}$

1 Department of Hepatogastroenterology, Regional University Hospital of Nancy, Nancy, France

2 Department of Digestive Surgery, Regional University Hospital of Nancy, Nancy, France

3 Department of Hepatogastroenterology, Dupuytren Hospital, Limoges, France

4 Gastroenterology and Endoscopy Unit, Pavillon L, Edouard Herriot Hospital, Lyon, France

5 BioEM, XLim, UMR 7252, CNRS, Limoges, France
Corresponding author

\section{Marion Schaefer, MD}

Service d'hépato-gastroentérologie, CHRU de Nancy, Rue du Morvan, 54511

Vandoeuvre les Nancy, France

m.schaefer@chru-nancy.fr

\section{References}

[1] Elton C, Makin G, Hitos K et al. Mortality, morbidity and functional outcome after ileorectal anastomosis. Br J Surg 2003; 90 : 59-65

[2] Poincloux L, Pezet D, Rouquette O. Successful recanalization of complete anastomotic stricture using colorectal endoscopic ultrasound-guided rendezvous thus allowing stoma reversal: two cases. Endoscopy 2016; 48: E353-E354

[3] Nunes G, Marques PP, Patita M et al. EUSguided recanalization of complete colorectal anastomotic stenosis using a lumenapposing metal stent. Endosc Ultrasound 2019; 8: 211-212

[4] Winkler J, Peyret C, Barraud-Blanc M et al. Recanalization of a complete colorectal anastomotic stenosis: an application of the Hot AXIOS stent. Endoscopy 2021; 53: E126-E127
Bibliography

Endoscopy 2022; 54: E429-E430

DOI 10.1055/a-1560-2199

ISSN 0013-726X

published online 8.9.2021

(c) 2021. Thieme. All rights reserved.

Georg Thieme Verlag KG, Rüdigerstraße 14,

70469 Stuttgart, Germany

\section{ENDOSCOPY E-VIDEOS}

https://eref.thieme.de/e-videos

口回 Endoscopy E-Videos is an open access online section, 自: reporting on interesting cases and new techniques in gastroenterological endoscopy. All papers include a high quality video and all contributions are freely accessible online. Processing charges apply (currently EUR 375), discounts and wavers acc. to HINARI are available.

This section has its own submission website at https://mc.manuscriptcentral.com/e-videos 